\title{
On the Merits of Vertical Divestiture
}

\author{
DAVID E. M. SAPPINGTON \\ Department of Economics, University of Florida, P.O. Box 117140, Gainesville, FL \\ 32611-7140, USA. E-mail: sapping@ufl.edu
}

\begin{abstract}
This paper demonstrates that vertical divestiture may increase consumer welfare even when the divestiture eliminates substantial scope economies and precludes only limited sabotage. More generally, the merits of vertical divestiture are shown to vary with: (1) the type and the intensity of competition in the retail market; (2) the locus of scope economies under vertical integration; and (3) the relative social values of consumers' surplus and profit.
\end{abstract}

Key words: regulation, sabotage, vertical divestiture.

\section{Introduction}

In settings where a vertically integrated provider (VIP) supplies vital inputs to its retail competitors, the VIP may have both the incentive and the ability to disadvantage (or "sabotage") rivals and thereby hinder industry performance. For example, in today's telecommunications industry, VIPs often supply local loops and/or switching services to competing suppliers of retail telecommunications services. ${ }^{1}$ Similarly, owners of railroad track, electricity distribution systems, and natural gas pipelines often provide retail services in direct competition with service providers that employ the owners' infrastructure. In such settings, a VIP may be able to exploit its position as the supplier of bottleneck wholesale services to disadvantage its retail competitors. By reducing the quality of the inputs it supplies to retail competitors or otherwise increasing their operating costs via some form of sabotage, the VIP may be able to secure a competitive advantage in the retail market, and thereby increase its profit. ${ }^{2}$

\footnotetext{
1 The local loop is the line that runs from the telecommunications supplier's central office to the customer's premise.

${ }^{2}$ Economides (1998) provides a seminal analysis of sabotage. Sibley and Weisman (1998), Mandy (2000), and Beard et al. (2001), among others, provide additional conclusions regarding the likely incidence and magnitude of sabotage in vertically related industries. Reiffen et al. (2000) and Zimmerman (2003) provide empirical evidence of sabotage.
} 
Because this incentive of a wholesale producer to sabotage retail rivals stems from the VIP's simultaneous operation in both the wholesale and retail stages of production, policymakers have considered vertical divestiture. Regulators in Great Britain, for example, have contemplated separating British Telecom into two independent companies, one of which would supply retail telecommunications services to final customers while the other would supply key wholesale services (e.g., local loops) to all suppliers of retail telecommunications services. ${ }^{3}$

Economists also have begun to analyze formally the merits of vertical divestiture. Crew et al. (2005) analyze a central tradeoff between sabotage and scope economies in a setting where retail rivals engage in Cournot competition. ${ }^{4}$ The authors observe that vertical divestiture (or "vertical separation") can eliminate sabotage, but also can sacrifice valuable economies of scope. ${ }^{5}$ If vertical separation precludes only limited economies of scope but eliminates a substantial amount of sabotage, vertical separation will outperform vertical integration. In contrast, integrated production will be preferred when scope economies are pronounced and the potential for sabotage is limited.

This research explores a variant of Crew et al. (2005)'s analysis and finds that their intuitive and seemingly indisputable conclusion can require modification in some settings. In particular, vertical separation is shown to secure a higher level of expected consumers' surplus than does vertical integration whenever retail firms engage in Bertrand price competition and the costs of non-integrated rivals are sufficiently similar. ${ }^{6}$ This is the case even when scope economies are pronounced and the potential for sabotage is limited under vertical integration.

\footnotetext{
3 The British telecommunications regulator, Ofcom, has decided to implement a form of structural separation that fosters independent decisions by the wholesale and retail divisions of British Telecom, but does not divide the divisions into independent companies (http://www.ofcom.org.uk/consult/condocs/telecoms_p2/statement/, visited April 29, 2006). In contrast, AT\&T was divided into independent providers of local and long distance telephone service in order to eliminate AT\&T's ability to employ bottleneck control of local exchange access to disadvantage rival suppliers of long distance telephone service. Crandall and Sidak (2002) review other settings in which various forms of vertical separation have been considered by policymakers around the world.

${ }^{4}$ See Beard et al. (1999) for an earlier discussion of this tradeoff.

5 Vertical divestiture occurs when a single firm that had been operating as a VIP is precluded from doing so in the future. Vertical separation encompasses both vertical divestiture and a ban on any firm - even one that had not previously operated as a VIP - serving as a VIP.

${ }^{6}$ Of course, Bertrand competition - like Cournot competition - is simply a caricature of the more complex interactions that comprise competition in practice. The key feature of Bertrand competition is the intense price competition fueled by homogeneous products and ample capacity that is dedicated before prices are determined (as can be the case in network industries, for example).
} 
The rationale for this conclusion is straightforward. Under Bertrand price competition, the retail price only reflects the VIP's cost (which, in turn, reflects the scope economies realized under vertical integration) when the most efficient retail rival has lower costs than the VIP and when the VIP's cost is the second-lowest cost in the industry. When the costs of non-integrated rivals are very similar and when the most efficient of these rivals has the lowest industry cost, a rival - not the VIP - is likely to have the second-lowest cost. Therefore, the likelihood that the benefits of scope economies are passed on to retail consumers in the form of lower prices is small when the costs of non-integrated rivals are highly correlated. Furthermore, the VIP will always employ sabotage to raise the price it charges for its retail product when it has lower costs than all its rivals. Consequently, retail consumers will be harmed systematically by sabotage and will benefit only infrequently from scope economies when rivals' costs are very similar under vertical integration. Therefore, vertical separation will secure lower prices for consumers than will vertical integration in this instance even when scope economies are pronounced and the potential for sabotage is limited under vertical integration.

This finding implies that the merits of vertical separation can vary with both the nature and the intensity of retail competition. The ensuing analysis also reveals that both the locus of scope economies and the social objective function can influence the optimal choice of industry structure. In particular, depending upon the prevailing input pricing rule, vertical integration can secure greater gains for consumers when a portion of the realized scope economies accrue upstream than when all scope economies accrue downstream. Vertical integration also can ensure greater total surplus than can vertical separation even when the latter industry structure secures greater consumers' surplus than the former. Indeed, if the VIP can choose its preferred level of sabotage after observing its rivals' realized costs, vertical integration always secures at least as much total surplus as does vertical separation.

These findings and others are developed as follows. The central elements of the simple model analyzed here are presented in section II. Section III provides a formal statement of the key findings. Section IV considers extensions of the basic model. Section V summarizes the analysis and suggests directions for future research.

\section{The Model}

A homogeneous product can be delivered to retail customers by an incumbent supplier or by any of several rival suppliers. $N$ potential consumers are each willing to pay up to $v$ dollars for one unit of the retail product. $v$ is assumed to be sufficiently large that all $N$ consumers purchase one unit 
of the product in equilibrium. ${ }^{7}$ No individual consumes more than one unit of the retail product, and resale of the product is prohibitively costly. Consumers purchase from the retail provider that charges the lowest price for the product. $^{8}$

Exactly one unit of a critical input is required to produce each unit of the retail product. The incumbent wholesale operator produces the input at constant unit cost and can sell the input to retail rivals at regulated unit price $w$. This regulated input price is assumed to (weakly) exceed the unit cost of producing the input, to abstract from settings where the wholesale producer might wish to terminate its operations or engage in sabotage in order to reduce the demand for its (unprofitable) wholesale service. For simplicity, the regulator is initially assumed to set the same input price under vertical integration and under vertical separation. ${ }^{9}$

Absent sabotage, the most efficient of the potential rival retail operators incurs unit cost $w+c_{d}^{R}$ in supplying the retail product. $c_{d}^{R}$ is the incremental unit cost of retail production for the most efficient (i.e., the least-cost) rival, given that it has already purchased the essential input. The corresponding unit cost of the rival with the second-lowest cost is $c_{d}^{R}+\Delta$, where $\Delta \geq 0$. The smaller is $\Delta$, the more similar are the costs of the most efficient rival and its most capable rival competitor, and thus the more intense is the potential price competition between these firms. This competition will be referred to as inter-rival competition. ${ }^{10}$

The level of $c_{d}^{R}$ is unknown at the time the industry structure is determined. The density function for $c_{d}^{R}$ is denoted $f\left(c_{d}^{R}\right)$. This density has strictly positive support on the interval $[c, \bar{c}]$. The corresponding distribution function, $F\left(c_{d}^{R}\right)$, is continuously differentiable. ${ }^{11}$ Initial uncertainty

\footnotetext{
7 The simplifying assumption of perfectly inelastic demand does not affect the central qualitative conclusions drawn below. Section IV reviews the primary changes to the analysis that arise when the demand for the retail product is sensitive to price.

${ }^{8}$ To avoid uninteresting technical complexities, it is assumed that if multiple firms set the same lowest price for the retail product, all consumers purchase from the most efficient of these firms. Furthermore, if the VIP and a rival have the same costs and set the same price, all consumers purchase from the VIP.

9 This simplifying assumption may be most appropriate in settings where the incumbent's unit cost of producing the input does not vary much as the prevailing industry structure changes. Section IV considers alternative settings and alternative regulatory policies.

10 The extent of inter-rival competition is exogenous and is assumed to be sufficiently intense as to justify the presumed absence of retail price regulation. Other authors (e.g., Lee and Hamilton, 1999) consider the optimal design of retail competition policy in vertically related industries.

${ }^{11} F(\cdot)$ can be viewed as the distribution function for the incremental unit cost of the most efficient rival. To provide a convenient parameterization, the corresponding unit cost of the second-most efficient rival is assumed always to be $\Delta$ units greater than the realized cost of the most efficient rival.
} 
about $c_{d}^{R}$ is natural because decisions about industry structure typically are infrequent, long-term decisions that are made before the production costs of all retail competitors are known. For simplicity, the incumbent's operating costs are assumed to be common knowledge at the time industry structure is determined. This familiarity with the incumbent's cost structure might arise, for example, from information obtained during a period of regulatory control, prior to deregulation of the retail industry. ${ }^{12}$

If the incumbent wholesale supplier undertakes sabotage $s$, the unit production costs of all retail rivals increase by $s$. Importantly, sabotage raises the costs of retail rivals, but has no corresponding impact on the costs of the wholesale operator's retail affiliate. ${ }^{13}$ The corresponding advantage that accrues to the wholesale operator's retail affiliate explains why the wholesale provider may engage in sabotage under vertical integration. ${ }^{14}$

In practice, regulators devote considerable resources to detecting, punishing, and limiting sabotage. ${ }^{15}$ The resulting regulatory constraints on sabotage are captured here simply by the parameter $\bar{s}$, which is the maximum level of sabotage the wholesale operator can undertake without detection (and punishment). ${ }^{16}$ When indifferent among multiple levels of

12 The key informational assumption is that industry producers know each others' costs when setting retail prices. The regulated input price $(w)$ is fixed in the model, and so is not affected by the regulator's information. More generally, limited knowledge of industry conditions can have important implications for regulatory policy. (See Armstrong and Sappington (2006), for example.) Vickers (1995) considers the merits of allowing a wholesale producer to compete against rival suppliers of a homogeneous retail product in a setting where the wholesale producer is privately informed about its operating costs, but cannot engage in sabotage.

13 Thus, sabotage enables the VIP to raise its rivals' costs, as in Salop and Scheffman (1983).

14 Sappington and Weisman (2005) analyze "self-sabotage", whereby a wholesale operator raises symmetrically the costs of all retail competitors, including the wholesale firm's retail affiliate.

15 Wood and Sappington (2004), for example, review and analyze the penalty system employed in the state of Michigan to limit the incentive of SBC Michigan to discriminate against retail rivals in its provision of wholesale telecommunications services. Stelzer (1997) discusses the difficulties of precluding sabotage in the electricity industry.

16 Alternative formulations are conceivable. Crew et al. (2005) and Mandy and Sappington (2006), for example, assume that the VIP faces a strictly increasing, strictly convex cost of implementing sabotage. This formulation may be more realistic in many settings. However, the simple formulation adopted here permits a closed-form comparison of outcomes under vertical separation and vertical integration while capturing the idea that the VIP can implement some, but not an unlimited amount of, sabotage. In practice, the amount of sabotage that a VIP attempts may increase as its wholesale profit margin declines. See, for example, Beard et al. (2001), Foros et al. (2002), and Kondaurova and Weisman (2003). 
sabotage, the wholesale operator is assumed to implement the smallest of these sabotage levels. ${ }^{17}$

The incumbent supplier's unit cost of production varies with the prevailing industry structure. Under vertical separation, this unit cost is $c_{u}+$ $c_{d}^{I}$. Vertical integration provides economies of scope, reducing the VIP's upstream unit cost from $c_{u}$ to $c_{u}-e_{u}$ (where $e_{u} \geq 0$ ) and reducing the VIP's incremental downstream (retail) unit cost from $c_{d}^{I}$ to $c_{d}^{I}-e_{d}$ (where $e_{d} \geq 0$ ). The VIP's aggregate unit cost reduction due to scope economies under vertical integration will be denoted $e \equiv e_{u}+e_{d}>0 .{ }^{18}$

The timing in the model is as follows. First, the incumbent's operating costs become known. Second, the regulator determines the industry structure (by specifying whether the incumbent wholesale producer is permitted to sell retail services) and sets the wholesale price for the input. Third, the monopoly wholesale supplier chooses its preferred level of sabotage. Fourth, the rivals' innate unit retail costs are realized and observed by all potential retail operators. ${ }^{19}$ Fifth, the potential retail producers set their retail prices simultaneously and independently. ${ }^{20}$ Sixth, consumers select their preferred retail supplier. Seventh, each retail operator produces to serve all realized demand for its product.

\section{Findings}

The following lemmas are useful in assessing the relative performance of vertical integration and vertical separation. Lemma 1 reports that the VIP will undertake the maximum feasible level of sabotage $(\bar{s})$ under vertical integration. The VIP prefers the maximum level of sabotage because it

\footnotetext{
17 This convention reflects the fact that when retail demand is price elastic and retail consumers purchase from a rival supplier, the wholesale operator often will have a strict preference for no sabotage, as is explained in section IV.

18 Vertical integration is assumed always to produce some cost reduction in order to ensure a non-trivial choice between vertical integration and vertical separation (which has the advantage of eliminating incentives for sabotage). In practice, vertical integration can fail to ensure cost reductions. Baxter (1991, p. 30) notes the difficulty of assessing the nature and magnitude of scope economies that arise under vertical integration in practice. Kaserman and Mayo (1991) examine how to estimate the magnitude of realized vertical economies.

${ }_{19}$ The presumed timing of the sabotage decision is natural when sabotage is achieved via major structural decisions that are not easily changed (e.g., the design or placement of primary telecommunications switches). Section IV considers an alternative timing, in which the incumbent wholesale producer can implement its preferred level of sabotage after observing the realized costs of retail suppliers.

20 Mandy and Sappington (2006) present a model of price competition in which a VIP can undertake cost-increasing sabotage. MS's analysis differs from the present analysis by admitting only a single rival firm, no cost uncertainty, and no possibility of vertical separation. MS admit product differentiation and demand-reducing sabotage.
} 
raises the costs of retail rivals to the greatest extent possible, and thereby endows the VIP with the most flexibility to raise its retail price without losing customers to rival producers. Lemma 2 states the obvious conclusion that the wholesale producer will refrain from sabotage under vertical separation. Sabotage provides no financial benefit to the wholesale producer when it has no financial stake in the incumbent retail producer. Lemma 3 characterizes equilibrium prices and production patterns under vertical integration. Lemma 4 provides the corresponding characterization under vertical separation. ${ }^{21}$

As the lemmas reveal, the most efficient rival will serve all retail customers under vertical separation whenever $c_{d}^{R}<c_{d}^{I}$. This rival will only serve all retail customers under vertical integration if its innate cost advantage is sufficient to overcome the disadvantages it faces due to sabotage and the VIP's scope economies (i.e., if $\left.c_{d}^{R}<c_{d}^{I}-(e+\bar{s})\right) .{ }^{22}$ Less efficient retail rivals never serve customers in equilibrium. However, when their cost disadvantage is not too pronounced, these potential rivals will influence equilibrium retail prices. For expositional simplicity, the ensuing analysis focuses on the setting in which this cost disadvantage is sufficiently small $\left(\Delta<c_{d}^{I}-\underline{c}\right)$ that the less efficient rivals affect equilibrium prices for some $c_{d}^{R}$ realizations. The key qualitative conclusions reported below persist more generally.

Lemma 1. The incumbent wholesale operator will implement the maximum feasible level of sabotage $(\bar{s})$ under vertical integration.

Lemma 2. The incumbent wholesale operator will refrain from sabotage (i.e., set $s=0$ ) under vertical separation.

Lemma 3. Under vertical integration, the VIP serves all retail customers if $c_{d}^{R} \geq \hat{c} \equiv c_{d}^{I}-e-\bar{s}$. The most efficient rival serves all retail customers if $c_{d}^{R}<$ $\hat{c}$. The equilibrium price under vertical integration, $p^{i}$, is:

$$
p^{i}= \begin{cases}w+c_{d}^{R}+\Delta+\bar{s} & \text { if } c_{d}^{R} \in[\underline{c}, \hat{c}-\Delta) \\ w+c_{d}^{I}-e & \text { if } c_{d}^{R} \in[\hat{c}-\Delta, \hat{c}) \\ w+c_{d}^{R}+\bar{s} & \text { if } c_{d}^{R} \in[\hat{c}, \bar{c}] .\end{cases}
$$

Lemma 4. Under vertical separation, the VIP serves all retail customers if $c_{d}^{R} \geq c_{d}^{I}$. The most efficient rival serves all retail customers if $c_{d}^{R}<c_{d}^{I}$. The

\footnotetext{
${ }^{21}$ The proofs of these lemmas and all formal conclusions are provided in the Appendix.

${ }_{22}$ The lowest possible downstream cost for a rival in the presence of full sabotage is assumed to be less than the VIP's corresponding cost under vertical integration, i.e., $\underline{c}+\bar{s}<c_{d}^{I}-e$.
} 
equilibrium price under vertical separation, $p^{s}$, is:

$$
p^{s}= \begin{cases}w+c_{d}^{R}+\Delta & \text { if } c_{d}^{R} \in\left[\underline{c}, c_{d}^{I}-\Delta\right) \\ w+c_{d}^{I} & \text { if } c_{d}^{R} \in\left[c_{d}^{I}-\Delta, c_{d}^{I}\right) \\ w+c_{d}^{R} & \text { if } c_{d}^{R} \in\left[c_{d}^{I}, \bar{c}\right] .\end{cases}
$$

The equilibrium prices reported in Lemmas 3 and 4 determine the levels of expected consumers' surplus that arise under vertical integration and vertical separation, respectively. Propositions 1 and 2 consider the incremental expected consumers' surplus that arises under vertical separation relative to vertical integration. This incremental surplus will be denoted $G \equiv E C S_{s}-$ $E C S_{i}$, where $E C S_{S}$ denotes expected consumers' surplus under vertical separation and $E C S_{i}$ denotes expected consumers' surplus under vertical integration.

Proposition 1 reports that the incremental expected consumers' surplus under vertical separation increases as inter-rival competition increases (i.e., as $\Delta$ declines). Proposition 2 reveals that expected consumers' surplus is always higher under vertical separation than under vertical integration when this potential inter-rival competition is sufficiently intense in the sense that the costs of the most efficient rival and the second-most efficient rival are sufficiently similar (so $\Delta$ is sufficiently close to zero).

Proposition 1. The incremental expected consumers' surplus under vertical separation relative to vertical integration increases as the costs of retail rivals become more similar; i.e., $d G / d \Delta<0$.

Proposition 2. Vertical separation secures higher expected consumers' surplus than vertical integration when the cost advantage that the most efficient rival enjoys over other rivals is sufficiently small; i.e., $G>0$ when $\Delta$ is sufficiently close to zero.

Before explaining the effects of inter-rival competition identified in Propositions 1 and 2, some more standard conclusions are recorded in Propositions 3 and 4. Proposition 3 reveals that the additional expected consumers' surplus secured under vertical separation typically declines as scope economies increase and as potential sabotage declines. Proposition 4 characterizes the conditions under which vertical integration secures greater expected consumers' surplus than does vertical separation (and vice versa) when rivals' retail production costs are uniformly distributed.

Proposition 3. When $\Delta>0$, the incremental expected consumers' surplus generated under vertical separation (relative to vertical integration) declines as scope economies increase and as potential sabotage declines; i.e., $d G / d e<0$ and $d G / d \bar{s}>0$. 


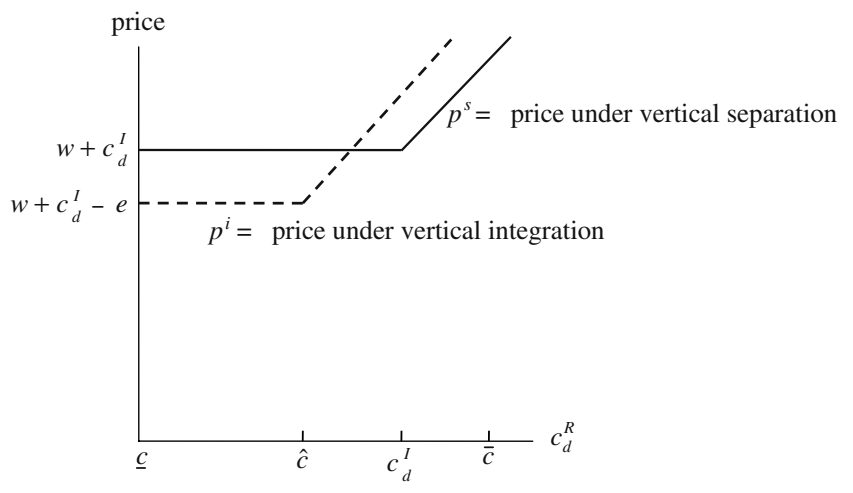

Figure I. Equilibrium Retail Price with No Inter-Rival Competition $(\Delta>\overline{\mathrm{c}}-\underline{\mathrm{c}})$.

Proposition 4. Suppose all unit retail cost realizations $\left(c_{d}^{R}\right)$ are equally likely (so $F(\cdot)$ is uniform). Then expected consumers' surplus is higher under vertical integration than under vertical separation if and only if the ratio of maximum potential sabotage to potential scope economies is sufficiently small relative to the cost differences among retail rivals; i.e.,

$$
E C S_{i}-E C S_{s} \underset{<}{\gtrless} 0 \Leftrightarrow \frac{\bar{s}}{e} \lesseqgtr \frac{\Delta}{>\bar{c}-\underline{c}-\Delta} .
$$

Figures I through III help to explain the conclusions reported in Propositions 1 through 4. Figure I depicts equilibrium prices in the benchmark setting where the most efficient rival has such a pronounced cost advantage over other rivals that these other potential operators never constrain the prices set by the most efficient rival. In essence, $\Delta$ is sufficiently large in the setting considered in Figure I that the only relevant price competition is between the incumbent supplier and the most efficient rival.

The standard intuition prevails here, as vertical integration introduces both a benefit and a cost in this setting with (effectively) no inter-rival competition. The benefit is lower retail prices due to the scope economies realized by the VIP. As Figure I reveals, this benefit arises for the lowest $c_{d}^{R}$ realizations, where the (most efficient) rival is the least-cost provider of the retail product. For these lower rival cost realizations, the rival serves all customers at the lowest retail price the incumbent is willing to set. This price is $w+c_{d}^{I}$ under vertical separation. This price is reduced to $w+c_{d}^{I}-e$ under vertical integration in this setting, reflecting the scope economies that arise when the VIP operates at both the wholesale and the retail stage of production.

The cost of vertical integration is the higher retail prices that result from sabotage. As is evident from Figure I, this cost is incurred when the rival's $\operatorname{cost}\left(c_{d}^{R}\right)$ is relatively high, and so the VIP finds it profitable to set a price equal to the rival's unit cost of production, and thereby preclude profitable 


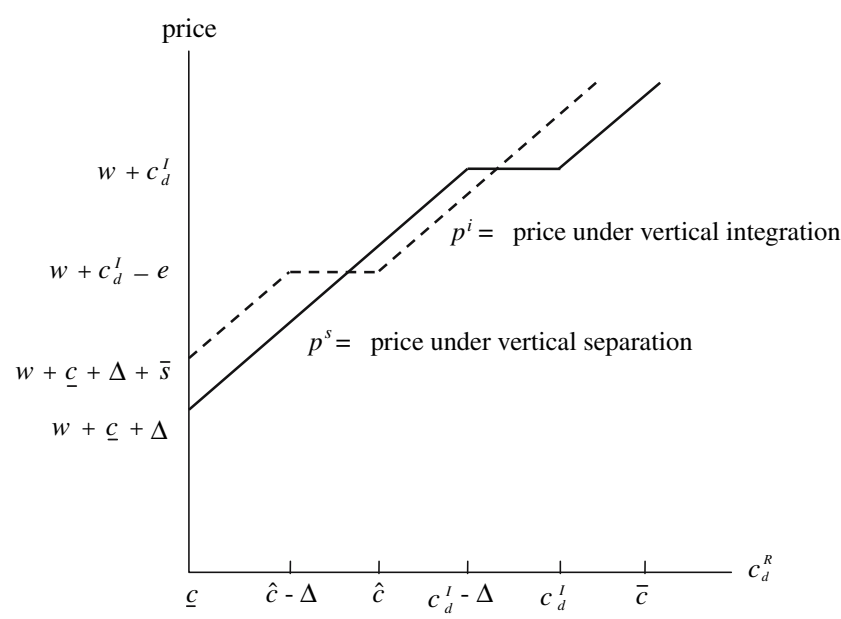

Figure II. Equilibrium Retail Price with Moderate Inter-Rival Competition $\left(\Delta \in\left(0, \mathrm{c}_{\mathrm{d}}^{\mathrm{I}}-\underline{\mathrm{c}}\right)\right)$.

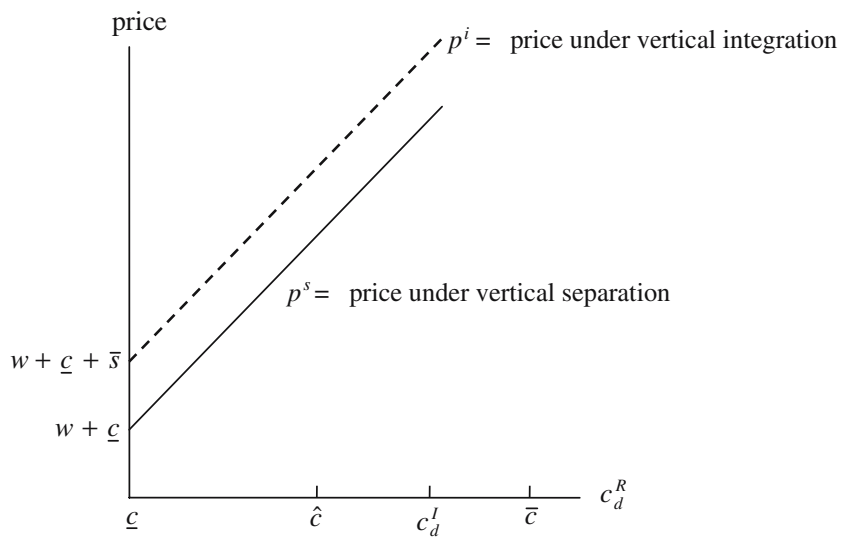

Figure III. Equilibrium Retail Price with Most Intense Inter-Rival Competition $(\Delta=0)$.

operation by the rival. For each realization of $c_{d}^{R}>\hat{c}$, sabotage raises the rival's unit cost - and thus the retail price - by $\bar{s}$ under vertical integration.

As Propositions 3 and 4 reveal, the ideal industry structure in this setting with no inter-rival competition depends upon the magnitudes of these benefits and costs. As intuition would suggest, vertical integration tends to generate a higher level of expected consumers' surplus than does vertical separation in this setting when scope economies are pronounced (so $e$ is large) and when there is limited potential for sabotage (so $\bar{s}$ is small). ${ }^{23}$

\footnotetext{
${ }^{23}$ Crew et al. (2005) provide corresponding conclusions in a setting where retail competitors engage in Cournot competition.
} 
Figure II illustrates the new considerations introduced by substantive inter-rival competition. Figure II, which depicts the conclusions drawn in Lemmas 3 and 4, reveals that competition from less efficient rivals can force the most efficient rival to reduce its retail price below the lowest price the incumbent supplier is willing to set for its product. The price reductions arise when a less efficient rival, rather than the VIP, has the second-lowest production cost. When $\Delta$ is large, the VIP will have the second-lowest production cost over a considerable range of $c_{d}^{R}$ realizations $\left(c_{d}^{R} \in[\hat{c}-\Delta, \hat{c})\right)$. As $\Delta$ declines, the second-most efficient rival becomes more likely to have a cost below $c_{d}^{I}-e$ when the most efficient rival does. Consequently, the range of $c_{d}^{R}$ realizations $\left(c_{d}^{R} \in[\hat{c}-\Delta, \hat{c})\right)$ in which the equilibrium retail price reflects the VIP's cost rather than the cost of the second-most efficient rival shrinks. Therefore, as $\Delta$ becomes small, the benefits of the scope economies that arise under vertical integration become less likely to be passed on to consumers in the form of lower retail prices.

This observation underlies Proposition 1, which concludes that the net benefits of vertical integration decline as inter-rival competition increases (i.e., as $\Delta$ declines). In the limit, as the cost advantage the most efficient rival enjoys over the other rivals disappears (so $\Delta=0$, as in Figure III), the equilibrium price charged by the most efficient rival always reflects the cost of the next most efficient rival, not the cost of the incumbent producer. In this limiting case where $\Delta=0$, the scope economies achieved under vertical integration affect the identity of the firm that serves all retail consumers, but not the equilibrium price. More generally, as Proposition 2 reports, vertical integration introduces costs (in the form of higher prices supported by sabotage) but little or no corresponding benefit when inter-rival competition is sufficiently intense.

In summary, more intense inter-rival competition reduces the likelihood that the scope economies realized under vertical integration will be passed on to consumers in the form of lower retail prices. Therefore, when interrival competition is sufficiently pronounced, vertical separation can ensure the highest level of consumers' surplus (by eliminating sabotage) even when vertical integration ensures substantial scope economies and only limited opportunity for sabotage.

\section{Extensions}

The purpose of this section is to explain how the foregoing comparison of vertical integration and vertical separation is altered when various elements of the simple model analyzed to this point are changed. Five modifications are considered. First, the price of the essential input may vary with the specified industry structure. Second, the cost of producing the input may be endogenous. Third, the incumbent wholesale producer may be able 
to choose its preferred level of sabotage after observing its rivals' realized production costs. Fourth, consumer demand for the retail product may not be perfectly inelastic. Fifth, the two industry structures might be judged on dimensions other than the level of expected consumers' surplus they generate.

\section{A. Variable Input Prices}

The analysis to this point has taken as given the regulated price of the essential input $(w)$, and assumed this price to be the same under vertical integration and vertical separation. Alternative assumptions merit consideration, particularly when vertical integration permits a substantial reduction in upstream production costs. When $e_{u}$ is large, the incumbent's unit cost of producing the essential input will be substantially lower under vertical integration than under vertical separation. A regulator might then set a lower input price under vertical integration $\left(w^{i}\right)$ than under vertical separation $\left(w^{s}\right)$.

In the setting analyzed in section III, any reduction in the input price results in an identical reduction in the equilibrium retail price. Therefore, a lower input price under vertical integration would increase the incremental consumers' surplus generated under vertical integration. Consequently, although the central considerations and tradeoffs analyzed above persist, an unequivocal preference for vertical separation is no longer guaranteed even when inter-rival competition is particularly intense (i.e., when $\Delta$ is close to zero) if the input price is systematically lower under vertical integration than under vertical separation. Indeed, even when $\Delta=0$, vertical separation will secure greater expected surplus than will vertical integration only if the maximum level of sabotage under vertical integration exceeds the extent to which the input price is lower under vertical integration (i.e., only if $\left.\bar{s}>w^{s}-w^{i}\right) .^{24}$

In summary, the systematic preference for vertical separation identified in Proposition 2 does not necessarily hold if regulated input prices reflect realized wholesale production costs and economies of scope reduce wholesale costs (in addition to or instead of retail costs). ${ }^{25}$

\footnotetext{
24 This conclusion follows directly from equations (A6)-(A8) in the Appendix. When $w^{i}<w^{s}$, the expression to the right of the equality in (A8) is decreased by the amount $w^{s}-w^{i}$. Therefore, when $\Delta=0, G=N\left[\bar{s}-\left(w^{s}-w^{i}\right)\right]$.

25 A pricing rule like the efficient component pricing rule (e.g., Baumol and Sidak, 1994) sets input prices to reflect both physical production costs and opportunity costs. The VIP's incentives for sabotage and aggressive retail price competition will be mitigated when input prices are adjusted to compensate the VIP for any reduction in retail profit caused by competitive entry. Reduced incentives for sabotage will tend to enhance the relative performance of vertical integration. In contrast, reduced incentives for aggressive
} 


\section{B. Endogenous Input Costs}

The simple model analyzed above assumes production costs are exogenous, and thereby abstracts from any differential incentives for innovation that might arise under vertical integration and vertical separation. A complete analysis of this important consideration is beyond the scope of the present research. However, some preliminary observations are available regarding the incentives of the incumbent producer to deliver non-contractible, personally costly effort to reduce wholesale production costs.

For simplicity, return to the benchmark setting where there is effectively no inter-rival competition because $\Delta$ is large. Also suppose that the scope economies under vertical integration, $e_{u}$ and $e_{d}$, continue to be exogenous and non-stochastic, but the basic wholesale unit cost, $c_{u}$, is endogenous and stochastic. Denote by $g\left(c_{u} \mid r\right)$ the conditional density function for the unit wholesale cost $c_{u} \in\left[\underline{c}_{u}, \bar{c}_{u}\right]$, where $r$ is the (unobservable) cost-reducing effort that the incumbent delivers at personal cost $K(r) .{ }^{26}$ Greater effort systematically increases the likelihood of the smaller $c_{u}$ realizations and reduces the likelihood of the larger $c_{u}$ realizations (in the sense of firstorder stochastic dominance). Let $w^{i}\left(c_{u}\right)$ denote the wholesale price that the regulator sets under vertical integration when wholesale unit cost $c_{u}$ is realized. Let $w^{s}\left(c_{u}\right)$ denote the corresponding wholesale price under vertical separation.

The incumbent's expected net return under vertical separation in this setting is readily shown to be:

$$
\underset{r}{\operatorname{maximum}}\left\{N \int_{\underline{c}_{u}}^{\bar{c}_{u}}\left[w^{s}\left(c_{u}\right)-c_{u}\right] g\left(c_{u} \mid r\right) d c_{u}-K(r)\right\} .
$$

The incumbent's corresponding expected net return under vertical integration is:

$$
\begin{gathered}
\underset{r}{\operatorname{maximum}}\left\{N \int_{\underline{c}_{u}}^{\bar{c}_{u}}\left[w^{i}\left(c_{u}\right)-c_{u}\right] g\left(c_{u} \mid r\right) d c_{u}-K(r)\right. \\
\left.+N e_{u}+N \int_{\hat{c}}^{\bar{c}}\left[c+\bar{s}-c_{d}^{I}+e_{d}\right] d F(c)\right\} .
\end{gathered}
$$

Footnote 25 Continued

pricing can increase the equilibrium retail price and thereby enhance the relative performance of vertical separation. The resolution of these conflicting effects merits further research, as does a complete assessment of the impact of different input pricing rules on the relative performance of vertical integration and vertical separation.

${ }^{26} K(\cdot)$ is an increasing, convex function of $r$. 
Because the last two terms in expression (2) do not vary with $c_{u}$ or with $r$, it is apparent from expressions (1) and (2) that the incumbent's incentives to reduce wholesale production costs will be identical under vertical integration and vertical separation in this setting unless the regulatory pricing policies differ in the two regimes. However, even under identical pricing policies, these incentives for cost reduction can differ systematically if the firm's cost-reducing effort affects the magnitude of the upstream scope economies $\left(e_{u}\right)$. If, for example, increased effort systematically increases the likelihood of high upstream scope economies, vertical integration can provide stronger incentives for cost-reducing effort than does vertical separation, ceteris paribus.

Again, then, the relative performance of vertical integration and vertical separation can vary with the extent to which scope economies are realized upstream. Just as upstream scope economies $\left(e_{u}>0\right)$ can enhance the relative performance of vertical integration when regulated input prices reflect realized wholesale costs, upstream scope economies that become more pronounced as the incumbent delivers more cost-reducing effort can enhance incentives for cost reduction under vertical integration.

\section{Targeted Sabotage}

The analysis to this point has assumed the incumbent wholesale operator chooses a single level of sabotage before observing the rivals' operating costs. Consider now the possibility that the incumbent can choose its preferred level of sabotage after observing the realization of $c_{d}^{R}$.

It is apparent that the incumbent will continue to refrain from sabotage under vertical separation in this setting. Under vertical integration, the incumbent will continue to implement the maximum level of sabotage $(\bar{s})$ when the rivals have relatively high production costs (i.e., when $c_{d}^{R} \geq \hat{c}$ ). The sabotage enables the incumbent to secure the patronage of all retail customers at a higher price than would be feasible if rivals' costs were not increased by sabotage. However, sabotage provides no strict gains for the incumbent when the cost advantage of the most efficient rival is so pronounced that it can profitably undercut the lowest retail price the incumbent is willing to set $\left(w+c_{d}^{I}-e\right)$ even when the incumbent undertakes the maximum level of sabotage $(\bar{s})$.

When the incumbent refrains from sabotage under vertical integration for the lower cost realizations $\left(c_{d}^{R}<\hat{c}\right)$, a lower equilibrium price will prevail whenever inter-rival competition forces the retail price to reflect the unit cost $\left(w+c_{d}^{R}+\Delta\right)$ of the second-most efficient rival. The lower retail prices from reduced sabotage increase expected consumers' surplus under vertical integration, and thereby reduce the extent to which expected consumers' surplus is higher under vertical separation than under vertical 
integration. However, the reduction is not so pronounced as to invalidate Proposition 2. The proposition continues to hold when the incumbent chooses its preferred level of sabotage after observing $c_{d}^{R} \cdot{ }^{27}$

\section{Price-Sensitive Demand}

The incumbent wholesale provider may have an additional incentive to reduce the incidence of sabotage when consumer demand for the retail product is not completely insensitive to price. In this case, a reduction in sabotage can enable the most efficient rival to set a lower price for its product and thereby generate greater retail demand, and hence greater demand for the essential input. This increased demand will produce higher profit for the incumbent when the regulated price for the input exceeds the incumbent's unit cost of producing the input. Consequently, the presence of price-sensitive retail demand can affect the equilibrium level of sabotage and the identity of the retail supplier. However, such price sensitivity will not alter the key qualitative conclusions reported in section 3 .

\section{E. Alternative Performance Measures}

The analysis to this point has focused on the level of expected consumers' surplus generated under vertical integration and under vertical separation. Other performance dimensions can also be relevant. Consider, for example, the total surplus generated under the two industry structures. With perfectly inelastic demand, the two structures generate the same total value in the retail market $(N v)$. Furthermore, at least in the setting with targeted sabotage where the wholesale producer can select its preferred level of sabotage after observing rivals' production costs, actual production costs are never increased by sabotage. (Sabotage only serves to deter operation by the rivals when $c_{d}^{R} \geq \hat{c}$ ). In contrast, the incumbent's actual operating costs when $c_{d}^{R} \geq \hat{c}$ are reduced by the scope economies that arise under vertical integration. Consequently, total surplus is always at least as high under vertical integration as under vertical separation in the setting with targeted sabotage.

These considerations imply that vertical integration can secure greater expected total surplus than does vertical separation even under conditions that ensure greater expected consumers' surplus under vertical separation

${ }^{27}$ The proof follows from the fact that when $\Delta \leq \bar{s}$ in this setting, $G \equiv E C S_{s}-E C S_{i}=$ $N\left[\bar{s}[1-F(\hat{c})]-\int_{c_{d}^{I}-\Delta}^{c_{d}^{I}}\left[c_{d}^{I}-c\right] d F(c)\right]$. This expression for $G$ follows from Lemmas 3 and 4 , where $p^{i}=w+c_{d}^{R}+\Delta$ for $c_{d}^{R} \in[\underline{c}, \tilde{c})$ and $p^{i}=w+c_{d}^{I}-e$ for $c_{d}^{R} \in[\tilde{c}, \hat{c})$, where $\tilde{c} \equiv \hat{c}-$ maximum $\{0, \Delta-\bar{s}$. 
than under vertical integration. This observation reflects the more general conclusion that the most appropriate industry structure typically will vary with the relevant social objective.

\section{Conclusions}

The prevailing wisdom suggests that vertical integration will secure lower prices for consumers than will vertical separation when the former industry structure introduces substantial scope economies and only limited opportunity for sabotage. Although this common wisdom is useful and compelling, it can require qualification in some settings. Under Bertrand price competition, the cost reductions that a VIP secures from scope economies are only passed on to retail consumers in the form of lower prices when the VIP has the second-lowest cost in the industry. This outcome is unlikely when the rivals' costs are very similar. Such congruence of rivals' costs makes it likely that either all rivals will have higher costs than the VIP or at least two rivals will have lower costs than the VIP. In the former case, the VIP will serve all retail customers at a price equal to the cost of the most efficient rival (inflated by sabotage). In the latter case, the most efficient rival will serve all retail customers at a price equal to the cost of the second-most efficient rival. In neither case does the equilibrium retail price reflect the scope economies that vertical integration provides, regardless of the magnitude of these scope economies.

This finding underscores the importance of considering both the extent and the exact nature of retail competition when determining the ideal industry structure. The foregoing analysis also identifies the need to consider both the locus and the magnitude of potential scope economies in any assessment of ideal industry structure. As explained in section IV, higher levels of consumers' surplus may be secured under vertical integration if some or all scope economies accrue upstream rather than downstream. The discussion in section IV also reveals the importance of considering the relevant social objective (e.g., the relative values of consumers' surplus and profit) when assessing the most appropriate industry structure.

A complete assessment of the optimal industry structure also must consider issues other than those addressed here. For instance, technological and demand uncertainty, private information about production possibilities and consumer preferences, and endogenous cost and quality all can affect the relative merits of vertical integration and vertical separation. ${ }^{28}$ Alternative cost structures, additional instruments that the regulator might employ to limit sabotage under vertical integration, and different forms of sabotage

\footnotetext{
${ }^{28}$ Crandall and Sidak (2002), for example, provide a useful discussion of some of these issues.
} 
also warrant consideration, as does the possibility of competition among wholesale operators. ${ }^{29}$ As suggested in section IV, the manner in which input prices (and input quality) are regulated also can affect the relative merits of vertical integration and vertical separation. These issues and others await future research.

\section{Acknowledgements}

I am grateful to Dennis Weisman, the Editor, Larry White, and two anonymous referees for very helpful comments and suggestions.

\section{Appendix}

PROOF OF LEMMA 1

If a rival serves all retail customers, the incumbent secures profit

$$
\Pi^{I 0}=\left[w-c_{u}\right] N
$$

If the incumbent serves all retail customers at price $p$, it secures profit

$$
\Pi^{I N}(p)=\left[p-c_{u}-c_{d}^{I}+e\right] N .
$$

(A1) and (A2) imply:

$$
\Pi^{I N}(p) \underset{<}{\gtrless} \Pi^{I O} \Leftrightarrow p \underset{<}{\gtrless} w+c_{d}^{I}-e .
$$

(A3) implies that the incumbent will never set a retail price below $w+c_{d}^{I}-e$.

When the realized incremental unit cost of the most efficient rival is $c_{d}^{R}$ and when the incumbent wholesale operator has implemented sabotage $s$, the lowest price at which a rival can operate profitably is $w+c_{d}^{R}+s$. Therefore, (A2) and (A3) imply that whenever

$$
w+c_{d}^{R}+\bar{s}>w+c_{d}^{I}+e \Leftrightarrow c_{d}^{R}>\hat{c},
$$

the incumbent's profit increases as the level of sabotage $s \in[0, \bar{s}]$ it implements increases. Consequently, because the sabotage never reduces the incumbent's profit, the incumbent will undertake sabotage $\bar{s}$ when the regulator implements vertical integration.

\footnotetext{
${ }^{29}$ Beard et al. (2001) demonstrate that wholesale competition can limit incentives for sabotage. Mandy and Sappington (2006) analyze both cost-increasing and demandreducing sabotage.
} 


\section{PROOF OF LEMMA 2}

Under vertical separation, sabotage never increases equilibrium retail sales and therefore never increases the wholesale operator's profit (which is the product of $w-c_{u}$ and equilibrium retail sales).

\section{PROOF OF LEMMA 3}

Lemma 1, (A3), and (A4) imply that the VIP will serve all retail customers at price $w+c_{d}^{R}+\bar{s}$ when $c_{d}^{R} \geq \hat{c}$ under vertical integration.

When $c_{d}^{R}<\hat{c}$, the most efficient rival can operate profitably at any retail price above $w+c_{d}^{R}-e$, even when sabotage $\bar{s}$ is undertaken. Consequently, the equilibrium retail price will not exceed $w+c_{d}^{R}-e$ when $c_{d}^{R}<\hat{c}$.

(A3) implies that the incumbent will never set a retail price below $w+c_{d}^{I}-e$. Consequently, the equilibrium retail price will be $w+c_{d}^{I}-e$ when $c_{d}^{R}<\hat{c}$, provided a rival other than the most efficient rival cannot operate profitably at this price; i.e., provided that

$$
w+c_{d}^{R}+\bar{s}+\Delta>w+c_{d}^{I}-e \Leftrightarrow c_{d}^{R}>\hat{c}-\Delta .
$$

When $c_{d}^{R} \in[\underline{c}, \hat{c}-\Delta)$, the most efficient rival must reduce the retail price to the level of the unit cost of the next most efficient rival to preclude profitable operation by this firm. Consequently, the equilibrium retail price will be $w+c_{d}^{R}+\bar{s}+\Delta$ when $c_{d}^{R} \in[\underline{c}, \hat{c}-\Delta)$.

\section{PROOF OF LEMMA 4}

From Lemma 2, the wholesale producer will refrain from sabotage under vertical separation. Consequently, Bertrand price competition will ensure production by the least-cost retail supplier at a price equal to the unit cost of the supplier with the next highest unit cost.

PROOF OF PROPOSITION 1

Lemma 3 implies:

$$
\begin{aligned}
E C S_{i}= & N[v-w]-N \int_{\underline{c}}^{\hat{c}-\Delta}[c+\Delta+\bar{s}] d F(c)-N \int_{\hat{c}-\Delta}^{\hat{c}}\left[c_{d}^{I}-e\right] d F(c) \\
& -N \int_{\hat{c}}^{\bar{c}}[c+\bar{s}] d F(c) .
\end{aligned}
$$


Lemma 4 implies:

$$
\begin{aligned}
E C S_{s}= & N[v-w]-N \int_{\underline{c}}^{c_{d}^{I}-\Delta}[c+\Delta] d F(c)-N \int_{c_{d}^{l}-\Delta}^{c_{d}^{l}} c_{d}^{I} d F(c) \\
& -N \int_{c_{d}^{l}}^{\bar{c}} c d F(c) .
\end{aligned}
$$

(A6) and (A7) imply:

$$
\begin{gathered}
\frac{G}{N}=\bar{s}+\left[c_{d}^{I}-\bar{s}-e\right][F(\hat{c})-F(\hat{c}-\Delta)]-\Delta\left[F\left(c_{d}^{I}-\Delta\right)-F(\hat{c}-\Delta)\right] \\
-c_{d}^{I}\left[F\left(c_{d}^{I}\right)-F\left(c_{d}^{I}-\Delta\right)\right]+\int_{\hat{c}}^{c_{d}^{I}} c d F(c)-\int_{\hat{c}-\Delta}^{c_{d}^{I}-\Delta} c d F(c) .
\end{gathered}
$$

(A8) implies:

$$
\begin{aligned}
\frac{d G}{d \Delta}= & N\left[-\hat{c} f(\hat{c}-\Delta)[-1]+c_{d}^{I} f\left(c_{d}^{I}-\Delta\right)[-1]\right. \\
& -\left[F\left(c_{d}^{I}-\Delta\right)-F(\hat{c}-\Delta)\right]-\Delta\left[f\left(c_{d}^{I}-\Delta\right)-f(\hat{c}-\Delta)\right][-1] \\
& -\left\{\left[c_{d}^{I}-\Delta\right] f\left(c_{d}^{I}-\Delta\right)[-1]-[\hat{c}-\Delta] f(\hat{c}-\Delta)[-1]\right\} \\
= & -N\left[F\left(c_{d}^{I}-\Delta\right)-F(\hat{c}-\Delta)\right]<0 .
\end{aligned}
$$

PROOF OF PROPOSITION 2

(A8) implies that $G=N \bar{s}+N Z(\Delta)$, where

$$
\begin{aligned}
Z(\Delta) \equiv & {\left[c_{d}^{I}-\bar{s}-e\right][F(\hat{c})-F(\hat{c}-\Delta)]-\Delta\left[F\left(c_{d}^{I}-\Delta\right)-F(\hat{c}-\Delta)\right] } \\
& -c_{d}^{I}\left[F\left(c_{d}^{I}\right)-F\left(c_{d}^{I}-\Delta\right)\right]+\int_{\hat{c}}^{c_{d}^{I}} c d F(c)-\int_{\hat{c}-\Delta}^{c_{d}^{I}-\Delta} c d F(c) .
\end{aligned}
$$

(A11) reveals that $\operatorname{limit}_{\Delta \rightarrow 0} Z(\Delta)=0$. Therefore, $\operatorname{limit}_{\Delta \rightarrow 0} G=N \bar{s}>0$.

PROOF OF PROPOSITION 3

(A8) implies:

$$
\begin{aligned}
\frac{d G}{d \bar{s}}= & N\{1-[F(\hat{c})-F(\hat{c}-\Delta)]-\hat{c}[f(\hat{c})-f(\hat{c}-\Delta)] \\
& -\Delta f(c-\Delta)+\hat{c} f(\hat{c})-[\hat{c}-\Delta] f(\hat{c}-\Delta)\} \\
= & N\{1-[F(\hat{c})-F(\hat{c}-\Delta)]\}>0 .
\end{aligned}
$$


Similarly, (A8) implies:

$$
\frac{d G}{d e}=-N[F(\hat{c})-F(\hat{c}-\Delta)]<0 \text { when } \Delta>0 .
$$

\section{PROOF OF PROPOSITION 4}

When $F(c)=\frac{c-\underline{c}}{\bar{c}-\underline{c}}$, (A8) implies:

$$
\begin{gathered}
G=\frac{N}{2[\bar{c}-\underline{c}]}\left\{2 \bar{s}[\bar{c}-\underline{c}]+2 \Delta \hat{c}-2 \Delta\left[c_{d}^{I}-\hat{c}\right]-2 \Delta c_{d}^{I}\right. \\
\left.+\left(c_{d}^{I}\right)^{2}-(\hat{c})^{2}-\left[\left(c_{d}^{I}-\Delta\right)^{2}-(\hat{c}-\Delta)^{2}\right]\right\} \\
=\frac{N}{[\bar{c}-\underline{c}]}\left\{\bar{s}[\bar{c}-\underline{c}]+\Delta\left[\hat{c}-c_{d}^{I}\right]\right\}=\frac{N}{\bar{c}-\underline{c}}\{\bar{s}[\bar{c}-\underline{c}-\Delta]-\Delta e\} .
\end{gathered}
$$

(A14) implies:

$$
G \leqq o \text { as } \frac{\bar{s}}{\overline{\bar{e}}} \leqq \frac{\Delta}{>} \bar{c}-\underline{c}-\Delta .
$$

\section{References}

Armstrong, Mark and David Sappington (2006) 'Recent Developments in the Theory of Regulation', in M. Armstrong and R. Porter eds., The Handbook of Industrial Organization. Amsterdam: Elsevier Science Publishers (forthcoming).

Baumol, William and J. Gregory Sidak (1994) 'The Pricing of Inputs Sold to Competitors', Yale Journal on Regulation, 11(1), 171-202.

Baxter, William (1991) 'Questions and Answers with the Three Major Figures of Divestiture', in B. Cole ed., After the Break-Up: Assessing the New Post-AT\&T Divestiture Era. New York: Columbia University Press, pp. 21-49.

Beard, T. Randolph, David Kaserman, and John Mayo (1999) 'Monopoly Leveraging, Path Dependency and the Case for a Local Competition Threshold for RBOC Entry into InterLATA Toll', in M. Crew ed., Regulation Under Increasing Competition, Boston. MA: Kluwer Academic Publishers, pp. 17-44.

Beard, T. Randolph, David Kaserman, and John Mayo (2001) 'Regulation, Vertical Integration, and Sabotage', Journal of Industrial Economics, 49(3), 319-333.

Crandall, Robert and J. Gregory Sidak (2002) 'Is Structural Separation of Incumbent Local Exchange Carriers Necessary for Competition?', Yale Journal on Regulation, 19(2), 335-411.

Crew, Michael, Paul Kleindorfer, and John Sumpter (2005) 'Bringing Competition to Telecommunications by Divesting the RBOCs', in M. Crew and M. Spiegel eds., Obtaining the Best from Regulation and Competition. Norwell, MA: Kluwer Academic Publishers, pp. 21-40.

Economides, Nicholas (1998) 'The Incentive for Non-Price Discrimination by an Input Monopolist', International Journal of Industrial Organization, 16(3), 271-284.

Foros, Øystein, Hans Jarle Kind, and Lars Søgard (2002) 'Access Pricing, Quality Degradation, and Foreclosure in the Internet', Journal of Regulatory Economics 22(1), 59-84.

Kaserman, David and John Mayo (1991) 'The Measurement of Vertical Economies and the Efficient Structure of the Electric Utility Industry', Journal of Industrial Economics, 39(5), 483-502.

Kondaurova, Irina and Dennis Weisman (2003) 'Incentives for Non-Price Discrimination', Information Economics and Policy 15(2), 147-171.

Lee, Sang Hyup and Jonathan Hamilton (1999) 'Using Market Structure to Regulate a Vertically Integrated Monopolist', Journal of Regulatory Economics, 15(3), 223-248. 
Mandy, David (2000) 'Killing the Goose that Laid the Golden Egg: Only The Data Know Whether Sabotage Pays', Journal of Regulatory Economics, 17(2), 157-172.

Mandy, David and David Sappington (2006) 'Incentives for Sabotage in Vertically-Related Industries', Journal of Regulatory Economics (forthcoming).

Reiffen, David, Laurence Schumann, and Michael Ward (2000) 'Discriminatory Dealing with Downstream Competitors: Evidence from the Cellular Industry', Journal of Industrial Economics, 48(3), 253-286.

Salop, Steven and David Scheffman (1983) 'Raising Rivals' Costs', American Economic Review 73(2), $267-271$.

Sappington, David and Dennis Weisman (2005) 'Self Sabotage', Journal of Regulatory Economics, Vol. 27(2), 155-175.

Sibley, David and Dennis Weisman (1998) 'Raising Rivals' Costs: The Entry of an Upstream Monopolist into Downstream Markets', Information Economics and Policy, 10(4), 451-470.

Stelzer, Irwin (1997) 'Vertically Integrated Utilities: The Regulators' Poison'd Chalice', Electricity Journal, 10(3), 20-29.

Vickers, John (1995) 'Competition and Regulation in Vertically Related Markets', Review of Economic Studies, 62(210), 1-17.

Wood, Lisa and David Sappington (2004) 'On the Design of Performance Measurement Plans in the Telecommunications Industry', Telecommunications Policy, 28(11), 801-820.

Zimmerman, Paul (2003) 'Regional Bell Operating Company Entry Into Long-Distance and Non-Price Discrimination Against Rival Interexchange Carriers: Empirical Evidence from Panel Data', Applied Stochastic Models in Business and Industry, 19(4), 269-290. 